\title{
The effect of surgical technique on hemodynamics, arterial oxygenation and pulmonary mechanics in radical prostatectomy operations
}

\author{
Yucel Yuce $^{1}$, Kutlu Hakan Erkal ${ }^{1}$, Cemal Goktas ${ }^{2}$, Bilal Eryildirim ${ }^{2}$, Kemal Sarica ${ }^{2}$ \\ ${ }^{1}$ Dr. Lutfi Kirdar Training and Research Hospital, Anaesthesiology and Reanimation Department, Kartal, Istanbul, Turkey; \\ ${ }^{2}$ Dr. Lutfi Kirdar Training and Research Hospital Urology Clinic, Istanbul, Turkey.
}

\begin{abstract}
Summary Objective: The effects of surgical technique on respiratory mechanics, arterial oxygenation and hemodynamics in radical prostatectomy operation were investigated.

Methods: The study was planned on ASA II-III, 40-65 years old, fourty patients scheduled for radical prostatectomy under general anesthesia. They were divided into two groups: perineal and suprapubic (Group P, $n=20$; Group S, $n=20$ ). Heart rate, mean arterial blood pressure, arterial oxygen saturation $\left(\mathrm{SpO}_{2}\right)$, partial pressure of end-tidal carbon dioxide $(\mathrm{PEtCO})$, Peak inspiratory pressure (PIP), plato pressure (Pplato), partial pressure of oxygen in arterial blood $\left(\mathrm{PaO}_{2}\right)$, partial pressure of carbon dioxide in arterial blood $\left(\mathrm{PaCO}_{2}\right)$ values were evaluated at 10 minutes after induction. After the position applied for surgery in the 30.60 and $90^{\text {th }}$ minutes, the Alveolar-arterial oxygen pressure gradient

$\left(P(A-a) O_{2}\right)$, the ratio of physiologic dead space over tidal volume (VD/VT), arterial to end tidal $\mathrm{CO}_{2}$ gradient $(\mathrm{P}(\mathrm{a}-\mathrm{et})$ $\left.\mathrm{CO}_{2}\right)$, static compliance (CS), dynamic compliance (CD) were assessed.

Results: In the assessment of groups, there were not statistical differences about mean blood pressure, heart rate, $\mathrm{SpO}_{2}$, $\mathrm{PetCO}_{2}, \mathrm{PaO}_{2}$, plateau pressure, and $\mathrm{P}(\mathrm{A}-\mathrm{a})$ values $(p>0.05)$. Peak inspiratory pressure was higher in Group $P$. Peak inspiratory pressure and plateau pressure increased with $\mathrm{CO}_{2}$ insufflation in Group P. $\mathrm{PaCO}_{2}$ and $\mathrm{P}($ a-et $) \mathrm{CO}_{2}$ were higher statistically significantly in Group 0 . There was no difference in terms of the $\mathrm{PetCO}_{2}$ values. VD/VT ratios were statistically significantly lower in the Group P.

Conclusions: Suprapubic surgery was shown to improve oxygenation and respiratory mechanics without causing any hemodynamic side effect in radical prostatectomy operation.
\end{abstract}

KEY WORDS: Radical prostatectomy; Position; Respiratory mechanics; Oxygenation.

Submitted 6 December 2016; Accepted 11 January 2017

\begin{abstract}
INTRODUCTION
With the ageing of world population, the burden of prostate cancer is expected to increase. Prostate cancer is the most prevalent cancer among men and the second leading cause of cancer-related death in men in Western industrialized countries (1). About 1.1 million cases of prostate cancer were diagnosed worldwide in 2012, accounting for $15 \%$ of all cancers in men (2). Today par-
\end{abstract}

allel to the increase in the incidence of the prostate cancer, the disease can be diagnosed at early stages and thus it is possible to perform some certain surgical procedures giving curative treatment chances where radical prostatectomy has become the golden standard for definitive treatment (3). With the developments in the surgical techniques and increase in anesthesic confidence, the morbidity of the radical prostatectomy has decreased significantly and the surgical mortality is $5 \%(4,5)$. Radical prostatectomy could be performed either via suprapubic or perineal approach and based on the method of dissection and the tools used. Each of these methods have its own advantages and disadvantages (4-6).

Related with this subject, radical perineal prostatectomy (RPP) was described in 1905 by Young (7). In addition to some surgical advantages of these two techniques one over the other from certain aspects (8), the position the patient during these approaches may also affect the course of the anestheasia a topic that has not been evaluated in detail so far.

In these patients; during general anesthesia arterial oxygenation may be disturbed because of several causes like functional instability of anesthesia equipment, endobronchial intubation, hypoventilation, increase in airway resistance, neuromuscular blockage and surgical position. In $53 \%$ of elective surgical procedures mild hypoxemic periods and in 20\% of them severe hypoxemic periods may be observed (9). It is found that the real causes of the deterioration of arterial oxygenation during anesthesia are atelectasia and ventilation and perfusion (V/Q) mismatch (10).

In cases with general anesthesia, due to the effects of the anesthesic agents, the surgical position and the anatomic region of the surgery atelectasis may occur in 90\% cases and it causes postoperative respiratory complications (11). Especially, it was thought that in cases with high risk this postoperative pulmonary complications of atelectasis cause increase in mortality and morbidity in patients without early diagnosis (12).

General anesthesia causes a decrease in Functional Residual Capacity (FRC) (5). FRC decreases in a 20\% ratio even in supine position. This decrease may be due to the decrease in inspiratory muscle tonus and also due to the increase in abdominal pressure and changes in 
thoracic blood volume. With induction of the anesthesia this decrease in FRC increases 10\% (13). Thus, general anesthesia may cause atelectasis inevitably.

Lithotomy position causes important physiologic changes. The decrease of FRC may induce the development of atelectasis and hypoxia. Upside down position with lithotomy advances these effects.

Elevation of the legs increases the venous return and exacerbates the congestive heart failure. Usually, mean arterial pressure increases but cardiac output does not change significantly. Inversely the rapid lifting down of the legs decreases the venous return and may cause hypotension. It is important to remember that the leg elevation redistributes pooled lower limb blood and this may lead to volume overload in susceptible individuals. Diaphragmatic movement can be limited severely by the weight of the abdominal viscera; this further reduces FRC and increases atelectasis. During surgery; several ventilation techniques can be performed to decrease the intraoperative alveolararterial oxygen gradient $\left(\mathrm{A}-\mathrm{a} \mathrm{DO}_{2}\right)(14)$.

In this study we aimed to investigate the effects of the patient position and the surgical technique on respiratory mechanics, arterial oxygenation and hemodynamics in radical prostatectomy operations.

\section{Patients ANd methods}

Following the approval by the Local Ethics Comittee of Kartal Dr. Lutfi Kirdar Training and Research Hospital, we performed our study in urology surgery room of hospital with 40 patients who underwent radical prostatectomy operation. Volunteer patients with informed consents in ASA I and II groups between 18-65 years of age without known DM and cardiopulmonary disorders were included to the study. The patients in whom complication occured during the surgery, hypotensive patients, the patients with previous Raynaud disease, Buerger disease, patients who underwent toracic surgery before and patients with negative modified Allen test were excluded from the study.

All patients were examined physically one day before the surgery and vital and laboratory findings were controlled. The hemoglobin and hematocrit levels, RBC, WBC, thrombocyte counts, coagulation parameters, serum electrolyte levels, liver function tests (SGOT, SGPT), BUN and creatinine levels, serum glucose levels, total bilirubin levels of all patients were studied. Modified Allen Test was performed in all patients. They were informed about the procedure and written informed consents were taken. The patients were randomised into two groups as perineal (Group P) and suprapubic (Group S). No premedication was performed to the patients.

When the patients were taken into the operation room, the monitorisation of them by ECG, non invasive blood pressure measurement and $\mathrm{SpO}_{2}$ was performed. $0.9 \%$ $\mathrm{NaCl}$ infusion at $8 \mathrm{ml} / \mathrm{kg} /$ hour rate was initiated after IV canulation with $22 \mathrm{G}$ canula. Radial artery canulation with $20 \mathrm{G}$ canula after local anesthesia was performed. Initial measurements of heart rates, blood pressures and $\mathrm{SpO}_{2}$ were recorded. For preoperative measurement arterial blood gas samples were taken.
For balanced anesthesia Tiopental $7 \mathrm{mg} / \mathrm{kg}$, Fentanyl $2 \mu \mathrm{g} / \mathrm{kg}$ and vecuronium $0,1 \mathrm{mg} / \mathrm{kg}$ were used.

Endotracheal intubation by spiral tubes with $7.0-8.5 \mathrm{~mm}$ internal diameters were performed and mechanical ventilation with Dräger Primus ventilator in IPPV mode with $50 \% \mathrm{~N} 2 \mathrm{O}-\mathrm{O}_{2}$ at $2 \mathrm{~L} / \mathrm{min}$ flow rate and with sevoflurane of $\mathrm{MAC}=1.0$ was initiated. During mechanical ventilation frequency of respiration was $12 / \mathrm{min}$, inspiration/expirationratio was 1:2 and tidal volume was $8 \mathrm{~mL} / \mathrm{kg}$. Second measurements (S1) were performed 10 minutes after induction at supine position. Then Ll was taken 15 minutes after lithotomy position, L2 was taken 30 minutes after lithotomy position, L3 was taken 60 minutes after lithotomy position and L4 was taken 90 minutes after lithotomy position. S2 was taken 15 minutes after supine position again.

The recorded parameters were heart rate, $\mathrm{SpO}_{2}$, invasive blood pressures, PIP, pPlateau, $\mathrm{ETCO}_{2}$ and tidal volume. The dynamic and static compliances of the both groups were calculated from the measured data. The arterial blood gas samples were taken simultaneously at the times which respiratory mechanics were recorded.

During the operation invasive mean arterial pressures, heart rates and $\mathrm{SpO}_{2}$ levels were recorded. When the operation terminated the patients were positioned again as supine and the inhalational anesthetics were also terminated. $100 \% \mathrm{O}_{2}$ was started. After initiation of the spontaneous respiration neuromuscular blockage was reversed with $0.01 \mathrm{mg} / \mathrm{kg}$ atropine and $0.04 \mathrm{mg} / \mathrm{kg}$ neostigmine. After adequte spontaneous respiration extubation was performed. The other medications during the operation and intraoperative complications were also recorded.

In randomised grouped patients PEEP was performed as $0 \mathrm{~cm} \mathrm{H}_{2} \mathrm{O}$ in group $\mathrm{S}$ and $10 \mathrm{cmH}_{2} \mathrm{O}$ in group $\mathrm{P}$. Intraabdominal insuflation pressure was constant as $<15$ $\mathrm{mm} \mathrm{Hg}$. Heart rates, blood pressures, $\mathrm{PEtCO}_{2}$, PIP, Pplateau, $\mathrm{PaO}_{2}, \mathrm{PaCO}_{2}$ levels were recorded 5 minutes after induction, 5 minutes after $\mathrm{CO}_{2}$ insuflation, 10 and 30 minutes after head up and right side position, 10 minutes after desuflation and at the recovery room. At the same time periods $\mathrm{P}(\mathrm{A}-\mathrm{a}) \mathrm{O}_{2}$, VD/VT, $\mathrm{P}($ aet $) \mathrm{CO}_{2}, \mathrm{CS}, \mathrm{CD}$ were calculated. When operation was terminated inhalational agent PEEP were also terminated. The durations of the operation and the anesthesia were also recorded.

\section{Statistical analysis}

For analysis of the data SPSS 17.0 program was used. During the evaluation of the data frequency ranges, means, standard deviations, percentages and crosstabs were used. For comparison of the groups independent sample t test, for cathegoric comparison Pearson chisquare and Fisher's exact tests were used. In multiple comparisons when there was difference between the groups, to find these groups in which there was difference Tukey HSD and Dunnet test was used.

\section{RESULTS}

There was no statistically significant difference between the groups according to age, body mass index (BMI) and the duration of the anesthesia $(\mathrm{p}>0.05)$ (Table 1). 
Table 1.

Demographic data and the duration of the anesthesia (mean $\pm S D$ ).

\begin{tabular}{|c|c|c|c|c|}
\hline & Perineal & Suprapubic & $t$ & $\mathrm{p}$ \\
\hline Age (year) & $59.47 \pm 8.72$ & $61.47 \pm 9.02$ & 0.21 & -0.682 \\
\hline Weight (kg) & $76.78 \pm 9.13$ & $77.15 \pm 9.923$ & -0.05 & 0.185 \\
\hline Length $(\mathrm{cm})$ & $165.28 \pm 7.42$ & $164.25 \pm 8.43$ & -1.16 & 0.192 \\
\hline BMI $\left(\mathrm{kg} / \mathrm{m}^{2}\right)$ & $26.95 \pm 2.88$ & $27.05 \pm 2.19$ & 0.86 & 0.430 \\
\hline $\begin{array}{l}\text { Duration of } \\
\text { anesthesia (min) }\end{array}$ & $130.06 \pm 40.02$ & $133.06 \pm 41.82$ & -0.33 & 0.680 \\
\hline
\end{tabular}

Table 2.

Distribution of the $\mathrm{PaCO}_{2}$ values in two groups (Mean $\pm S D$ ).

\begin{tabular}{|r|c|c|c|c|}
\hline $\mathbf{P a C O}_{\mathbf{2}}$ & Group $\mathbf{P}(\mathbf{n}=\mathbf{2 0})$ & Group $\mathbf{S}(\mathbf{n}=\mathbf{2 0})$ & $\mathbf{t}$ & $\mathbf{p}$ \\
\hline Before induction & $34.60 \pm 3.19$ & $34.55 \pm 3.30$ & 1.155 & 0.001 \\
\hline After induction & & & & \\
10. $\mathrm{min}$ & $35.90 \pm 3.19$ & $43.35 \pm 6.90$ & 0.366 & 0.001 \\
20. $\mathrm{min}$ & $38.50 \pm 3.35$ & $35.05 \pm 2.95$ & 0.653 & 0.001 \\
30. $\mathrm{min}$ & $44.65 \pm 6.67$ & $32.72 \pm 5.53$ & 0.024 & $<0.001$ \\
60. $\mathrm{min}$ & $42.2 \pm 16.21$ & $33.35 \pm 5.72$ & 1.51 & $<0.001$ \\
90. $\mathrm{min}$ & $41.3 \pm 44.14$ & $41.76 \pm 7.28$ & 0.811 & 0.001 \\
\hline
\end{tabular}

Table 3.

Distribution of the $\mathrm{P}\left(\mathrm{a}\right.$-et) $\mathrm{CO}_{2}$ values in two groups (Mean $\pm S D$ ).

\begin{tabular}{|c|c|c|c|}
\hline $\mathbf{P}\left(\mathbf{a}\right.$-et) $\mathbf{C O}_{\mathbf{2}}$ & Group $\mathbf{P} \mathbf{( n = 2 0 )}$ & Group $\mathbf{S}(\mathbf{n}=\mathbf{2 0})$ & $\mathbf{p}$ \\
\hline Before induction & $9.74 \pm 5.32$ & $9.12 \pm 3.47$ & 0.023 \\
\hline After induction & & & \\
10. $\min$ & $11.45 \pm 5.49$ & $11.65 \pm 2.23$ & 0.098 \\
20. $\mathrm{min}$ & $12.55 \pm 7.35$ & $9.48 \pm 3.09$ & 0.610 \\
30. $\min$ & $11.61 \pm 5.25$ & $10.72 \pm 3.62$ & 0.402 \\
60. $\mathrm{min}$ & $10.32 \pm 8.01$ & $9.30 \pm 3.43$ & 0.377 \\
90. $\mathrm{min}$ & $12.75 \pm 5.42$ & $11.61 \pm 6.75$ & 0.345 \\
\hline
\end{tabular}

In group $\mathrm{P}$ and $\mathrm{S}$, there was no statisitically significant difference in basal, 10, 20, 30, 60 and 90 minutes after induction $\mathrm{PaCO}_{2}$ values ( $\left.\mathrm{p}>0.05\right)$ (Table 2).

In group P basal, 10, 20, 30, 60 and 90 minutes after induction mean $\mathrm{PaCO}_{2}$ values are statistically significantly different $(\mathrm{p}=0.0001)$. Basal $\mathrm{PaCO}_{2}$ values were lower than the values at 10,20,30,60 and 90 minutes after induction $(\mathrm{p}<0.001)$ (Table 2).

In group $S$ basal, 10, 20, 30, 60 and 90 minutes after induction mean $\mathrm{PaCO}_{2}$ values are statistically significantly different $(\mathrm{p}=0.0001)$. Basal $\mathrm{PaCO}_{2}$ values were higher than the values at 10,20,30,60 and 90 minutes after induction $(\mathrm{p}<0.001)$ (Table 2).

There was no statistically significant difference between groups according to the $\mathrm{P}(\mathrm{a}-\mathrm{et}) \mathrm{CO}_{2}$ levels at all times $(p>0.05)$. In group $P$, it was found that the increase in $\mathrm{P}(\mathrm{a}$-et $) \mathrm{CO}_{2}$ at the time before induction in response to the level at 20 minutes after induction was statistically significant $(\mathrm{p}<0.01)$ (Table 3$)$.

There was no statistically significant difference between two groups according to the mean PIP values before induction $(\mathrm{p}=0.002)($ Table 4$)$.
In group S 10, 20, 30, 60 and 90 minutes after induction PIP values were not statistically significantly different $(\mathrm{p}=0.153)($ Table 4).

In group P 10, 20, 30, 60 and 90 minutes after induction PIP values were statistically significantly different $(\mathrm{p}=$ $0.013)$. The PIP values were significantly lower than 10 , 20, 30, 60 and 90 minutes after induction PIP values $(\mathrm{p}<0.05)$ (Table 4).

There was no statistically significant difference between groups according to the before induction $\mathrm{CD}$ levels (p > 0.05) (Table 5).

The difference between CD levels at all times in Group P and the CD levels in Group S at 10, 20, 30, 60 and 90 minutes and after induction were statistically significant $(\mathrm{P}<0.001)$ (Table 5).

The mean VD/VT at 20 min after induction in Group P was higher than the value of Group $S$ and this was statistically significant $(\mathrm{p}<0.05)$. In Group P the VD/VT values at 60 and 90 minutes after induction were higher in response to the value at 30 minutes after induction and this was also statistically significant $(\mathrm{p}<0.01)$ (Table 6).

Table 4.

Distribution of the PIP values in two group (Mean $\pm S D$ ).

\begin{tabular}{|r|c|c|c|c|}
\hline PIP & Group $\mathbf{P}(\mathbf{n}=\mathbf{2 0})$ & Group $\mathbf{S}(\mathbf{n}=\mathbf{2 0})$ & $\mathbf{t}$ & $\mathbf{p}$ \\
\hline Before induction & $17.42 \pm 4.51$ & $17.80 \pm 4.39$ & -7.28 & 0.002 \\
\hline After induction & & & & \\
10. $\mathrm{min}$ & $21.80 \pm 3.82$ & $19.80 \pm 4.21$ & -7.70 & 0.018 \\
20. $\mathrm{min}$ & $23.23 \pm 3.64$ & $18.20 \pm 4.01$ & -8.41 & 0.048 \\
30. $\mathrm{min}$ & $21.15 \pm 3.71$ & $17.80 \pm 3.31$ & -11.38 & 0.005 \\
60. $\mathrm{min}$ & $22.32 \pm 3.38$ & $18.80 \pm 4.25$ & -10.07 & 0.009 \\
90. $\mathrm{min}$ & $21.44 \pm 34.11$ & $16.80 \pm 3.71$ & -11.05 & 0.008 \\
& & & & \\
\hline
\end{tabular}

Table 5.

Distribution of the $C D$ values in two groups (Mean $\pm S D$ ).

\begin{tabular}{|l|c|c|c|}
\hline CD & Group P $(\mathbf{n}=\mathbf{2 0})$ & Group $\mathbf{S}(\mathbf{n}=\mathbf{2 0})$ & $\mathbf{p}$ \\
\hline Before induction & $27.42 \pm 4.62$ & $26.32 \pm 5.50$ & $(\mathbf{p}>0.05)$ \\
\hline After induction & & & \\
10. $\min$ & $23.80 \pm 3.83$ & $15.91 \pm 4.21$ & $<0.001$ \\
20. $\min$ & $23.23 \pm 3.65$ & $14.24 \pm 5.02$ & $<0.001$ \\
30. $\mathrm{min}$ & $24.15 \pm 3.82$ & $13.50 \pm 3.41$ & $<0.001$ \\
60. $\mathrm{min}$ & $22.32 \pm 3.49$ & $15.86 \pm 4.26$ & $<0.001$ \\
90. $\mathrm{min}$ & $23.44 \pm 34.12$ & $16.78 \pm 5.72$ & $<0.001$ \\
\hline
\end{tabular}

Table 6.

Distribution of the VD/VTvalues in two groups (Mean $\pm S D$ ).

\begin{tabular}{|l|c|c|c|}
\hline VD/VT & Group P $(\mathbf{n}=\mathbf{2 0})$ & Group $\mathbf{S}(\mathbf{n}=\mathbf{2 0})$ & $\mathbf{p}$ \\
\hline Before induction & $0.25 \pm 0.09$ & $0.21 \pm 0.10$ & $<0.001$ \\
\hline After induction & & & \\
10. $\min$ & $0.26 \pm 0.12$ & $0.24 \pm 0.10$ & $<0.001$ \\
20. $\mathrm{min}$ & $0.22 \pm 0.100$ & $0.19 \pm 0.12$ & $<0.001$ \\
30. $\mathrm{min}$ & $0.23 \pm 0.12$ & $0.12 \pm 0.07$ & $<0.001$ \\
60. $\mathrm{min}$ & $0.29 \pm 0.100$ & $0.12 \pm 0.07$ & $0.009 *$ \\
90. $\mathrm{min}$ & $0.24 \pm 0.09$ & $0.22 \pm 0.08$ & $<0.001$ \\
\hline
\end{tabular}




\section{Discussion}

We examined the effects on respiratory mechanics and blood gas analysis of the exaggerated lithotomy position for radical perineal prostatectomy. We found that, with the exception of the carbon dioxide tension, all respiratory parameters were significantly affected by the change of position from the supine to the exaggerated lithotomy position. Significant changes were found in airway pressures, compliance and airway resistance, the work of breathing and arterial oxygen tension.

Different patient positions have been used during radical prostatectomy procedures. The primary surgical methods used for prostatectomy include radical retropubic prostatectomy and radical perineal prostatectomy. The advantages of the perineal approach are decreased blood loss due to the dissection of the prostate without ligation of the deep dorsal venous complex of the penis, direct visualisation of the vesicourethral anastomosis, a reduced operative time, minimisation of surgical stress and a smooth recovery after surgery (9). But it may cause the pelvic and abdominal organs to move in a cephalad direction, leading to compression of the diaphragm and lungs and causing a significant decrease in functional residual capacity.

During the surgery different positions were performed after anesthesia induction for different surgical procedures. Usually anesthesia induction is performed at supine position and for many procedures supine position is the only position during the operation. But sometimes the position of the patient is changed due to the surgical procedure and the status of the patient.

Radical retropubic prostatectomy is performed with patients in the supine position, whereas in radical perineal prostatectomy, patients are placed in an exaggerated lithotomy position. The exaggerated lithotomy position used in our study differs from these positions.

The patients' legs are first elevated, the knee joints are then flexed $90^{\circ}$ and the feet and ankles are securely fastened (15).

The patient position required for surgery affects the cardiac function and haemodynamic parameters (15). Having information about human anatomy and physiology and phyical equlibrium are important for chosing the most proper position for the patient. With the ideal position, the patient's physiology must not change and no soft tissue and skeletal damages should be observed. These positions should preserve the cardiovascular and respiratory reserves, the airway, venous interventions and the monitorisations of the patients. They should also provide the most proper position for the surgical procedure.

The pulmonary perfusion and ventilation are affected by gravity, chest wall mechanics and the movements of the diaphragm. In a conscious patient lower zones of the lung are ventilated good. Small changes in pressures can cause larger changes in lung volumes. During the operation in supine, prone and lateral positions lower lung zones are properly perfused. In patients with neuromuscular blockage and mechanical ventilation, tidal volume decreases by the decrease in diaphragmatic movements. Pulmonary ventilation decreases and thus ventilation perfusion mismatch occurs. Additionally, pressure towards the mediastinum from upper parts and abdominal pressures from the lower parts make the ventilation difficult. FRC decreases $40 \%$ during anesthesia in supine position.

Lithotomy position can be combined with upside down position for promoting the surgical procedure. Lower extremities should be opened towards both sides symmetrically and the lumbar lordosis should be supported. For protection of the sciatic, obturatory and femoral nerves, flexion of the hips and the knees $>90^{\circ}$. During the duration of the position perfusion pressures must be maintained.

According to the surgical position in addition to all body systems arterial blood gas values also change. The developing monitorisation and ventilation with improvement in technology can provide us proper follow up of the patients and rapid interventions to the possible complications can be performed. The primary surgical methods used for prostatectomy include radical retropubic prostatectomy and radical perineal prostatectomy. The advantages of the perineal approach are decreased blood loss due to the dissection of the prostate without ligation of the deep dorsal venous complex of the penis, direct visualisation of the vesicourethral anastomosis, a reduced operative time, minimisation of surgical stress and a smooth recovery after surgery (15).

Casati et al. studied the effects on physiological dead space to tidal volume ratio after placing patients in different positions. The values reported were $0.36(0.05)$, 0.38 (0.06), and 0.40 (0.04) in the supine,

Trendelenburg $\left(20^{\circ}\right)$, and prone positions, respectively. This ratio was significantly higher in prone $(\mathrm{p}<0.01)$ but not in the Trendelenburg $\left(20^{\circ}\right)$ position compared with the supine position (16).

Radical retropubic prostatectomy is performed with patients in the supine position, whereas in radical perineal prostatectomy, patients are placed in an exaggerated lithotomy position. The standard lithotomy position or combined lithotomy-Trendelenburg position are commonly used for rectal and perineal operations (17).

Several studies have reported the respiratory effects of the prone, lateral decubitus positions, including during laparoscopic procedures utilising a pneumoperitoneum $(16,17)$.

In our study, we report a significant decrease in $\mathrm{PaO}_{2}$ $(\mathrm{p}<0.0005)$ but no significant increases in $\mathrm{EtCO}_{2}$ and $\mathrm{PaCO}_{2}$. The decrease in expiratory tidal volume (2.4\%) and increase in physiological dead space to tidal volume ratio (11.1\%), were not sufficient to produce an increase in carbon dioxide tension.

Rauh et al. reported that measurements taken 10 min following the creation of a pneumoperitoneum (with an intra-abdominal pressure of $15 \mathrm{~mm}-\mathrm{Hg}$ ) produced peak inspiratory pressure increases of $35 \%$ and dynamic lung compliance decreases of $27 \%$. The results of Rauh et al. are comparable to our study in that after patients were placed in an exaggerated lithotomy position, peak inspiratory pressure increased $34.0 \%$ and dynamic lung compliance decreased $27.4 \%$. Therefore, it is likely that the exaggerated lithotomy position imposes similar effects on airway pressure and lung compliances as the creation of a pneumoperitoneum of $15 \mathrm{~mm}-\mathrm{Hg}$ (17). 
Ryniak et al. reported increases in $\mathrm{PaCO}_{2}$ and shunt fraction and a decrease in $\mathrm{PaO}_{2}$ associated with the exaggerated lithotomy position. Changes in hemodinamics and pulmonary mechanics were compared in patients placed in the exaggerated lithotomy position and in the supine position (18).

Transperineal access of the retropubic area requires the exaggerated lithotomy position, and this position is used most commonly in radical perineal prostatectomy and urethral reconstruction. However, this position exerts considerable stress on the lower back and imposes a significant additional gradient for the perfusion of the lower limbs. Complications of this position include compartment syndrome, neuropraxia, lower back strain, venous air embolism and rhabdomyolysis (18).

Although radical perineal prostatectomy is associated with the advantages of decreased blood loss, minimised surgical stress and smoother postoperative recovery when compared with radical retropubic prostatectomy, the exaggerated lithotomy position clearly could compromise respiratory function. In our study, $50 \%$ of patients (12/24) were 65 years of age or older, and no patients developed respiratory complications during the operation.

We examined the effects on respiratory mechanics and blood gas analysis of the exaggerated lithotomy position for radical perineal prostatectomy. We found that, with the exception of the carbon dioxide tension, all respiratory parameters were significantly affected by the change of position from the supine to the exaggerated lithotomy position. Significant changes were found in airway pressures, compliance and airway resistance, the work of breathing and arterial oxygen tension.

The mechanisms underlying these alterations are not fully elucidated. However, the selective elevation of the sacrum and lower lumbar area by folded sheets or a large wedge may cause the pelvic and abdominal organs to move in a cephalad direction, leading to compression of the diaphragm and lungs and causing a significant decrease in functional residual capacity.

In the exaggerated lithotomy position (flexed and head down), as compared with the supine position, Ryniak et al. reported a significant decrease in $\mathrm{PaO}_{2}(\mathrm{p}<0.001)$ and a significant increase in $\mathrm{PaCO}_{2}(\mathrm{p}<0.001)(18)$.

In our study, we report a significant decrease in $\mathrm{PaO}_{2}$ $(\mathrm{p}<0.0005)$ but no significant increases in $\mathrm{EtCO}_{2}$ and $\mathrm{PaCO}_{2}$.

In obese patients, excessive elevation of the perineal area, and/or over- flexion of the thighs, may produce a restricted space between the abdomen and thighs. This may severely compromise respiratory mechanics, leading to inadequate ventilation or even barotrauma.

Transperineal access of the retropubic area requires the exaggerated lithotomy position, and this position is used most commonly in radical perineal prostatectomy and urethral reconstruction. However, this position exerts considerable stress on the lower back and imposes a significant additional gradient for the perfusion of the lower limbs (19).

Although radical perineal prostatectomy is associated with the advantages of decreased blood loss, minimised surgical stress and smoother postoperative recovery when compared with radical retropubic prostatectomy, the exaggerated lithotomy position clearly could compromise respiratory function.

In our study, $50 \%$ of patients were 65 years of age or older, and no patients developed respiratory complications during the operation. In conclusion, we have found that the exaggerated lithotomy position produces significant changes on respiratory mechanics and blood oxygenation when compared to the supine position.

Although this position was well tolerated by most patients, careful monitoring of the respiratory variables is required and it is important to be aware of the potential negative respiratory effects. Further work is required to evaluate in more detail the effects of this position in obese patients and patients with co-existing lung disease.

\section{Conclusions}

In conclusion, patient position during radical prostatectomy directly affects operative time. Even though success and complication rates are not related to position, placing the patient in lithotomy position with an extended leg seems to make the surgery easier and faster, specially when operating males. We have found that the exaggerated lithotomy position produces significant changes on respiratory mechanics and blood oxygenation when compared to the supine position.

\section{REFERENCES}

1. Heidenreich A, Bellmunt J, Bolla M, et al. EAU guidelines on prostate cancer. Part 1: screening, diagnosis, and treatment of clinically localized disease. Eur Urol. 2011; 59:61-71.

2. Ferlay J, Soerjomataram I, Dikshit R, et al. Cancer incidence and mortality worldwide: sources, methods and major patterns in GLOBOCAN 2012. Int J Cancer. 2015; 136:E359-E386.

3. Djavan B, Eckersberger E, Finkelstein J, et al. Oncologic, functional and cost analysis of open, laparoscopic and robotic radical prostatectomy. Eur Urol Suppl. 2010; 9:371-78.

4. Smith AJ. Principles of open radical prostatectomy: Applied to Robotic-assisted laparoscopic prostatectomy. In: Smith AJ, Tewari AK, editors. Robotics in urologic surgery. Philadelphia, PA: Saunders Elsevier; 2008. p. 69-78.

5. Walsh PC. Anatomic radical retropubic prostatectomy; in Walsh PC, Retik AB Vaughan ED Jr. Wein M (eds): Campbell's Urology, ed 7, Philadelphia, W.B Saunders Co., 1998, vol 3, pp 2565-2588.

6. Gillitzer R, Thüroff JW. Relative advantages and disadvantages of radical perineal prostatectomy versus radical retropubic prostatectomy. Crit Rev Oncol Hematol. 2002; 43:167-90

7. Young HH. The Early Diagnosis and Radical Cure of Carcinoma of the Prostate. Bulletin of the Johns Hopkins Hospital. 1905; VXVI:315-321.

8. Leung AC, Melman A. Radical Perineal Prostatectomy: A More Optimal Treatment Approach Than Laparoscopic Radical Prostatectomy in Obese Patients? Rev Urol. 2005; 7:48-52.

9. Moller JT, Johannessen NW, Berg H. Hypoxaemia during anaesthesia- An observer study. Br J Anaesth. 1991; 66:437-44.

10. Karcz M, Papadakos PJ. Respiratory complications in the postanesthesia care unit: A review of pathophysiological mechanisms. Can J Respir Ther. 2013; 49:21-9. 
11. Hedenstierna G, Edmark L. Mechanisms of atelectasis in the perioperative period. Best Pract Res Clin Anaesthesiol. 2010; 24:157-69.

12. Tusman G, Böhm SH, Warner DO, et al. Atelectasis and perioperative pulmonary complications in high-risk patients. Curr Opin Anaesthesiol. 2012; 25:1-10.

13. Hewlett A, Hulands G, Nunn J, et al. Functional residual capacity during anaesthesia III: Artificial ventilation. Brit J Anaesth. 1974; 46:495-503.

14. Blum JM, Blank R, Rochlen LR. Anesthesia for patients requiring advanced ventilatory support. Anesthesiol Clin. 2010; 28:25-38.

15. Anema JG, Morey AF, McAninch JW, et al. Complications related to the high lithotomy position during urethral reconstruction. J Urol. 2000; 164:360-63.
16. Casati A, Salvo I, Torri G, et al. Arterial to end-tidal carbon dioxide gradient and physiological dead space monitoring during general anaesthesia: effects of patients' position. Min Anestesiol. 1997; 63:177-82.

17. Rauh R, Hemmerling TM, Rist M, et al. Influence of pneumoperitoneum and patient positioning on respiratory system compliance. J Clin Anesth. 2001; 13:361-65.

18. Ryniak S, Brannstedt S, Blomqvist H. Effects of exaggerated lithotomy position on ventilation and hemodynamics during radical perineal prostatectomy. Scand J Urol Nephrol. 1998; $32: 200-03$

19. Choi SJ, Gwak MS, Ko JS, et al. The effects of the exaggerated lithotomy position for radical perineal prostatectomy on respiratory mechanics. Anaesthesia. 2006; 61:439-43.

\section{Correspondence}

Yucel Yuce, MD

dryyuce@gmail.com

Kutlu Hakan Erkal, MD

hakerkal@yahoo.com

Dr. Lutfi Kirdar Training and Research Hospital, Anaesthesiology

and Reanimation Department, Kartal, Istanbul, Turkey

Cemal Goktas, MD

cemalgoktas@yahoo.com

Bilal Eryildirim, MD (Corresponding Author)

bilaleryildirim@yahoo.com

Kemal Sarica, MD

saricakemal@gmail.com

Dr. Lutfi Kirdar Training and Research Hospital Urology Clinic,

Istanbul, Turkey 